\title{
Calidad de atención del servicio de anestesiología del Hospital Centro de Salud durante el período mayo- junio de 2019
}

\author{
Dami PG. ${ }^{1}$, Gómez Cascales AE. ${ }^{1}$, Gramajo JL. ${ }^{1}$, Pacheco AF. ${ }^{1}$, Scro ME. ${ }^{1}$, Véliz Juica G. ${ }^{1}$ \\ 1 Hospital Centro de Salud, San Miguel de Tucuman, Argentina. \\ Introducción: La calidad percibida por parte de los pacientes resulta de gran valor en el mejoramiento continuo esta. \\ Es más probable que un paciente satisfecho cumpla con las recomendaciones y busque ayuda médica. Todo punto \\ débil de asistencia es potencialmente mejorable, y ésta es la razón de ser de la calidad. \\ Métodos: Se determinaron como criterios de inclusión paciente mayor a 18 años, conscientes, que sean capaces de \\ responder al cuestionario, programados electivamente, ASA I y II. Como criterios de exclusión se prescindieron \\ pacientes que ingresen en emergencias, procedentes de UTI y UTIM, ambulatorios, pacientes cuya cirugía se hubiese \\ suspendido por cualquier motivo o cualquier tipo de alteración que impida contestar el cuestionario, como alteración \\ del estado de consciencia y retraso madurativo. Se utilizo una ficha técnica como instrumento de recolección de \\ datos, obtenida de un trabajo de investigación realizado por el Dr. Bolaño, consistente en una encuesta cerrada, cuya \\ recolección de datos se realizó en dos fases: pre-anestesia y post-anestesia, volcando los datos en Microsoft Excel y \\ finalizando un análisis descriptivo de las variables involucradas en este estudio.
}

Resultados: Se analizaron a todos los pacientes que ingresaron a quirófano para cirugía programada en el Hospital Centro de Salud Z. S. durante los meses de mayo y julio de 2019. Luego del análisis destaca el poco porcentaje de pacientes que conocen a su médico anestesiólogo tanto antes como después de la cirugía. Aumento el conocimiento del anestesiólogo de un 19\% a un $23 \%$ en el postoperatorio, y con respecto al cirujano de un $51 \%$ ascendió a un $72 \%$ respectivamente. Comparando la proporción de pacientes que conocían los riesgos anestésicos antes y después de la misma, se notó un aumento en el porcentaje de pacientes que tenían conocimiento sobre los riesgos de la anestesia, pasando de un $46 \%$ a un $62 \%$ en el postoperatorio y la opinión acerca si el anestesiólogo es médico aumento de un $74 \%$ a un $79 \%$ en el postoperatorio.

Conclusiones: Los resultados obtenidos en este trabajo muestran, en general, escaso conocimiento de los pacientes a cerca de su anestesiólogo, y de todas las actividades inherentes a él y al procedimiento anestésico propiamente dicho. El anestesiólogo es un especialista de la medicina que es poco reconocido, del cual se desconocen sus actividades principales aun entre los médicos en formación. Esto no cambia para la población en general la cual tiene una percepción todavía más alejada de la realidad.

https://doi.org/10.25237/congresoclasa2019.72 